\title{
Abortion in Islam: The Roles of Cultures and Virtues in Medical Ethics
}

El aborto en el Islam: El papel de las culturas y las virtudes en la ética médica

Kola Abímbola

Howard University - United States

Washington, DC, United States

kolapo.abimbola@howard.edu

\begin{abstract}
This paper examines the roles of culture and virtues in medical ethics. It argues that principlism, which is the general approach to medical ethics in Western societies, is not comprehensive enough to fully understand how medical moral dilemmas are resolved in Western and non-Western societies. This is because principlism overlooks the importance of culture and virtues in the medical profession. To fully understand the nature of medico-ethical decision-making, we need to shift focus from principles to the virtues of the medical profession itself and the cultures of the societies within which medicine is practiced. I illustrate these claims with the example of abortion in Islamic ethics.
\end{abstract}

Keywords: Abortion in Islam; Applied Ethics; Cultural Pluralism; Philosophical Ethics; Principlism

\section{RESUMEN}

Este artículo examina el papel de la cultura y las virtudes en la ética médica. Sostiene que el principialismo, que es el enfoque general de la ética médica en las sociedades occidentales, no es lo suficientemente completo para comprender plenamente cómo se resuelven los dilemas morales médicos en las sociedades occidentales y no occidentales. Esto se debe a que el principialismo pasa por alto la importancia de la cultura y las virtudes en la profesión médica. Para comprender plenamente la naturaleza de la toma de decisiones médico-éticas, tenemos que pasar de los principios a las virtudes de la propia profesión médica y a las culturas de las sociedades en las que se practica la medicina. Ilustro estas afirmaciones con el ejemplo del aborto en la ética islámica.

Palabras clave: Aborto; Islam; ética aplicada; pluralismo cultural; ética filosófica; principialismo 


\section{INTRODUCTION}

This paper is an exploration of the roles of virtues in contemporary medical culture. I contend that the current discourse on medical ethics underrates the significance of the cultural ethos that binds medicine together as a biological science. I shall argue that the importance of cultural ethos can be better explained with the revival of some version or the other of the virtue ethics theories of Plato and Aristotle (Barnes 2004). Although G.E.M. Anscombe (1958) and Alasdair MacIntyre (1981) have written extensively on virtue ethics, the import of virtue ethics as a philosophical alternative to deontological and consequentialist theories of biomedical ethics has not been fully appreciated. Even though several scholars (e.g., E.A. Pellegrino 1993, 2002, and Rosamond Rhodes, 2007, 2001, 1995, Gardiner 2003) have used virtue ethics to challenge the common assumption that medical ethics is/should be about principles, rules, and consequences, there are three gaping gaps in these discussions of virtues in medical ethics; namely, the culture of medicine itself as a discipline; its impacts on the virtues of the professionals who put medicine into practice, and the significance of the cultural values of the community within which medicine is practiced.

In Western societies, principlism is assumed by many to be the best method for resolving medical ethical dilemmas (Beauchamp, T. L., \& Childress, J. F. 2001). Principlism is an approach to the resolution of moral dilemmas that requires the application of a set of four ethical principles, viz: respect for autonomy (doctors must favor the choices of competent patients); nonmaleficence (doctors shouldn't inflict harm); beneficence (procedures should be of benefit to the patient's health); and justice (give to each that which is their due). These principles are said to be objective, universally acceptable, and globally applicable.

In any medico-ethical decision-making situation, appraisal standards (including the four ethical principles of principlism) are applied within a background context (such as legal institutions, medical associations, religious beliefs, etc.). These backgrounds regulate (and in some situations dictate) the allowable and unacceptable maneuvers of the decision-maker.

Moreover, these background standards are social. Consider, for instance, the American Medical Association's Code of Medical Ethics. Chapter 2 of the Code states that:

Chapter 2 on Ethics of Consent, Communication \& Decision Making

Help your patients make well-considered decisions about their care and treatment by reading up on medical ethics of consent. (https://cutt.ly/fQd1kg3)

All physicians that practice in the United States must, of necessity, operate within the allowable confines of this community standard, irrespective of that physician's individual beliefs. Hence community rules and standards:

- Give weight to the acceptability of a decision;

- Function as the measure against which individual decisions are assessed; and,

- Operate as a common value for assessing any decision as good or bad.

Principlism's claim that it is possible to produce culture-free and value-free medico-ethical decisions is just plainly false! The cultural tradition of medicine, of which we, as biological subjects, are a part, determines the types of character traits we should look for in virtue medical ethics. In medical culture, these traits must involve the virtues of the individual and the virtues of the profession itself. 


\section{THE CULTURAL GOODS OF MEDICINE}

The word, culture, has at least two everyday usages: on the one hand, it means 'high culture, the 'best' exemplars of a society's achievements and products in the arts, literature, music, science, and technology. The second sense of the word culture is that in which it refers to the artificial cultivation and growth of microscopic organisms, species, and plants (Gripsrud 1989). This second sense of the word derives its meaning from the verb 'to cultivate,' 'to husband' (in the sense of agricultural techniques). These two senses of culture are linked: for, not only are achievements in the arts, literature, science, etc., "artificial" in that they are human creations: the elements of "high" (and, of course, "low") culture have to be cultivated, learned and transmitted-otherwise, they will wither away and die.

Medicine is intricately intertwined with cultural goods in these two senses above: it is about the achievements of a society in its quest to understand itself as the socio-biological knower, just as much as it is about the cultivation and transference of knowledge about us as the medical subject (Abimbola 2007). There are four further dimensions to the two cultural aspects of medicine: the communal, the individualistic, the archival, and the practical.

Three, medicine is communal: it is the shared set of beliefs, practices, and methods that make up a society's collective bank of knowledge on the prevention, alleviation and curing of diseases and injuries. Medicine in this communal sense is reflected in the social activities of people as a group (Abimbola, 2013). One of the most transparent illustrations of the communal dimensions of medicine is public health concerns in the protection, promotion, and restoration of people's health. Solutions to public health concerns require the combination of various scientific skills and social action. Public health aims to improve and maintain the health of all people through collective or social activities. Although the communal dimensions of medicine are easily exhibited in public health, medicine as a social institution can be conceived of as a domain of inquiry that has as its goals the prevention and reduction of disease, premature death, and disability; the prolongation of life and the promotion of physical and mental health; the control of community infections; the training and organization of professionals to diagnose and treat the infirm; and the development of other social mechanisms for the achievement of these social goals.

In this sociologistic/communal sense, medicine has some key characteristics. First of all, in every society, medicine is about the social production of knowledge that has to be learned and transmitted from individuals to individuals. This implies that medicine is one of those fields of human knowledge that studies and deals with the organic, environmental, psychological, and biological dimensions of human existence. Medicine is, therefore, a dynamic field of human endeavor that is subject to variation, improvement, progress, and control over time.

Four, culture in medicine is not just about socially variable communal practices. It is also psychologistic because it manifests individual beliefs about ontology, metaphysics, and methods for realizing and achieving health, wholeness, and wellness. The point here really is that "all knowledge is to some extent concerned with the knower: our attempts to know things about the natural world are also part of a much larger attempt to understand ourselves" (Evans 2005, p.3). And in understanding ourselves as the knowing subject, we uphold various medico-cultural beliefs. At one level, these beliefs might just be about faith. But at another (practical) level, they may form the content of heuristic action-guiding principles that moderate and affect human action.

A fifth fundamental way medicine is a culture good is that it is the repository of concepts, ideas, words, methods, and other symbolic structures that individuals rely on in their day-to-day living. In this sense of the word, medicine as a cultural good is not just about beliefs and values that we 
uphold; it is also about internalizing and operationalizing these beliefs and values in regulating and controlling the organic, environmental, psychological, and psychological biological dimensions of human existence.

Culture can therefore be found not merely in communal medical practices (Abimbola, 2007). Neither is it confined to explicitly proclaimed beliefs. Cultural assumptions can also be found in unstated psychological assumptions about how we understand, develop, treat and encounter ourselves in the practice of medicine. In this psychologistic sense of medical culture, medical values are not just about explicitly proclaimed beliefs; they are about those unstated convictions that implicitly guide and govern practical conduct in issues of health, wholeness, and wellness. We may refer to these dimensions of culture as practical beliefs. This would be a fifth sense in which medicine encompasses culture.

Here is a quick recapitulation of these goods: (i) medicine is a repository of a society's achievements in the human sciences. These achievements rely on; (ii) cultivated techniques that must be learned, nurtured, and transmitted. In the process of accepting and sharing them, they (iii) become part of a community or society's general belief structures. At the same time (iv), they will become part of the specific beliefs accepted by particular individuals. Finally, (v) the acceptance and reliance of (i) to (iv) makes medical beliefs practical-beliefs; that is, they become heuristic action-guiding principles on the basis of which we moderate, regulate and control action and inaction in issues of health, wholeness, and wellness.

It is the fifth sense of how medicine is about the culture that is most important to our discussion of virtues in ethics. For in relying on the achievements, techniques, methods, and processes that have been developed in medicine, we need to distinguish between two sets of things: (i) two types of "agents"; viz, healthcare professional and patients, and (ii) two types of moral and ethical issues concerning these different agents; viz; action-focused issues of morality; and agent-focused issues of morality. These two sets of distinctions are intricately linked. For concerning each type of agent, we could ask questions about their "actions" and questions about their character. When we are interested in ethical issues that are about their actions, we focus on whether there are any ethical principles, rules, obligations, duties, and rights that ground or justify their actions. The principles, rules, duties, and obligations on the basis of which we can adjudge actions as morally right or wrong cannot tell us much about the virtues of an agent's character (Abimbola 2013). The judgment that actions are morally right or wrong does not tell us anything about agents' virtues or character traits. Differently put, action may be morally justified based on a principle or rules even though the agent did not wholeheartedly operate on virtues such as honesty or generosity as reasons for her actions. So, even when actions are adjudged ethically to be correct, they may still lack moral virtue.

Consider, for instance, the accidents and emergency doctor who carries out her legal and moral obligations on a Friday night simply because they are her obligations. She hates having to work in accidents and emergencies on Friday nights. She dislikes being placed in a situation where the interests of patients override her interests in going to the pictures on Friday nights. She hates and intensely dislikes the accident-prone drunk teenagers she has to treat; she does not feel friendly or compassionate towards them, but she nonetheless acquiesces with their needs because her obligations require her to consider their interests. Even though this doctor may perform the morally correct action, she would lack a character trait essential to virtue medical ethics. To possess this virtue is to be a particular type of person who doesn't simply act because she is obligated to act, but the sort of person who acts because she has the disposition to act. 
The community, environment, setting, and culture of medicine inform our expectations and judgments about the virtues of these agents, and this is a sixth sense in which medicine is a cultural good. That is, the practical-beliefs on the basis of which medicine operates are not merely heuristic action-guiding principles (Abimbola 2002). Instead, they also inform and give context to our understanding of the character traits we hold in high esteem in health care professionals (and patients) (Abimbola 2013, Locke 1989).

\section{VIRTUES: BEYOND PRINCIPLES AND RULES}

In the previous section, I maintained that the community environment within which physicians, patients, and other actors in medical settings operate generates its own set of background criteria. I call these the cultural goods of medicine. These background cultural criteria inform, dictate, and regulates decision-making. In this section, I will shift focus to the virtues of physicians.

\section{Physicians as Fiduciaries of Patient}

Rosamond Rhodes $(2007,2001,1995)$ has written extensively on the distinctiveness of the ethics of medicine. Her position is that the doctor-patient relationship is a fiduciary-principal type of relationship in which fiduciary (doctor) is expected to be loyal, trustworthy, and caring to their patients. This fiduciary-principal relationship leads to the position that medical ethics is not an extension of ordinary everyday morality: it is an ethics based on virtues rather than mere principles and rules. Rhodes' argument for the uniqueness of medical ethics is predicated upon the following considerations.

In typical everyday contexts, it is usually appropriate to adopt a negative conception of moral responsibility in the sense that by refraining from killing someone, theft, deception, etc., we are often adjudged to have acted in a morally responsible manner. But doctors can be criticized for failing to act because, in many healthcare settings, they have a positive duty to respond to patients' needs and to actively promote their patients' health. Doctors are, of course, not the only types of professionals who are placed under specific obligations to act. The point here is that given the role of doctors in the medical sciences, when they are on duty or when they have voluntarily assumed an obligation to act, they are placed in circumstances where their characters may be critiqued and evaluated as caring, compassionate, trustworthy, or reliable.

\section{Nonjudgmental}

Second, in typical everyday contexts, people are supposed to be judgmental in their choice of whom they associate with. It is considered good judgment to choose friends wisely. It is deemed reasonable to educate and instruct our children and loved ones about dissociating and selecting their friends and company. Doctors are, however, not supposed to be judgmental in the practice of their profession because they are expected to treat all patients without discrimination.

The previous point also underscores another issue. In the exercise of their professions, doctors are supposed to care for strangers; and they are expected to cede the responsibility of the medical care of their loved ones to other doctors because their affection could adversely affect their clinical judgment.

\section{Confidentiality}

In regular day-to-day life, people are at liberty to divulge information about their personal lives to those they deem fit. As such, people freely exchange information and gossip about their experiences. Doctors, however, are under a general ethical (and legal) obligation to keep what 
their patients tell them confidential. This obligation is, of course, not absolute as there are situations where the law requires doctors to breach confidentiality, just as there are situations where the law allows doctors to breach confidentiality. For instance, sharing information about patients with other members of the health care team is not usually viewed as a breach of privacy. Nonetheless, even in those situations, doctors must take reasonable precautions to ensure that confidential information about their patients does not fall into the wrong hands.

Part of the reason why confidentiality has been a significant part of the ethics of the doctorpatient relationship is that we usually divulge sensitive, illegal, and embarrassing information about ourselves to our doctors. To provide the best medical treatment for us, doctors typically ask us probing questions about our sexual activities, drug usage, diets, etc. In typical day-to-day contexts, such probing questions usually are regarded as rude and improper. Still, in the practice of medicine, they are essential to the effective treatment of patients.

\title{
Autonomy
}

In many day-to-day contexts, individuals are regarded as autonomous agents who are often at liberty to make decisions and choices about their actions and inactions, and as long as their choices do not violate laws and they do not adversely affect the interest of others, we are supposed to respect their choices. Although this general legal and moral consideration of autonomy also forms the basis of the doctor-patient relationship, in many situations, doctors may be morally and ethically bound not to presume their patients' autonomy. The doctor's obligations in these respects could include advising someone who has coronary heart disease to stop smoking, just as it might consist of applying to a court for an injunction to allow blood transfusion on a pregnant Jehovah's Witness so that a cesarean section can be performed to save the lives of mother and child.

\section{The Distinctiveness of Medicine}

The conclusion that Rosalind Rhodes correctly draws from these observations about the doctorpatient relationship is that the principles-based approach to medical ethics overlooks the distinctiveness of ethics in medicine:

\begin{abstract}
.... foundational principle of the ethics of medicine is "trust." It is essential for clinicians and the institution of medicine to be trustworthy and seek the trust of patients and society in all of their actions ... all doctors must accept and seek trust and deserve it as their moral law. In deciding what to do and how to do it, they must pay attention to promoting trust and not eroding it. And in molding themselves as physicians, they must focus on making themselves trustworthy practitioners (Rhodes, 2007, p.75).

...patients and society rely upon medicine to be trustworthy. Their reliance and the conditions of medicine's monopoly over medical practice explain the importance of trust and the importance of clinicians conforming to "the standard of care." The role-based trust of medicine means that doctors are not counted upon for their personal judgment but for providing treatment according to medical science and the well-accepted principles of medical practice (Rhodes, 2007, p.76).
\end{abstract}

Based on her analysis of the roles of trust and care within the medical contexts, Rhodes concludes that we need to pay more attention to the attributes and qualities of the doctor. Patients are more likely to trust their doctors if doctors are perceived as professionals who care about patients' health. The trust patients place in their doctors will to a large extent, depend upon 
whether doctors respect the autonomy of their patients by paying attention to the patient's view of what is good for her (Rhodes, 2007). But a patient cannot make an informed decision about what is good for her if doctors do not tell the truth. Hence truth-telling becomes part of the standards of virtues based on which we can evaluate and assess doctors. Other doctor-specific virtues that flow from the central role of trust in Rhodes' model are professional competence, confidentiality, non-sexual regard (i.e., the doctor-patient relationship should not have any sexual overtones), nonjudgmental regard (i.e., doctors should promote the health and wellness of their patients without first judging whether that patient is a worthy patient), and assessing decisionmaking capacity (i.e., ethics requires doctors to constantly evaluate the ability of their patients to make reasonable judgments about their treatment choices.) In sum, Rhodes' position is that the centrality of trust in the profession of medicine urges us to pay more attention to the character of doctors as moral agents.

\section{The Character of Doctors as Moral Agents}

Although Edmund Pellegrino's approach to medical ethics differs in significant respects from that of Rhodes', his approach is also a virtues-based one in which he maintains that a good doctor will be someone who exhibits the following character traits:

Fidelity to trust - because the physician has invited trust, the patient cannot avoid it, and it is essential if healing and helping are to occur.

Benevolence - because the prime precept of medical ethics since the Hippocratic era has always been acting for the good of the patient, and of course, avoiding all harm.

Intellectual honesty - because medicine is a powerful instrument for good and harm depending on how medical knowledge and skill are used. Knowing when one does not know and having the humility to admit it and to obtain assistance are virtues crucial to avoiding harm.

Courage - because the physician must expose herself to the dangers of contagion, to possibilities of physical harm in emergency situations, and to political retribution in regimes that enlist physicians in torture, interrogation of prisoners, and deceptions of various kinds....

Compassion - because in any chronic or complicated illness or clinical decision, the physician must enter the predicament of the patient, to feel something of the patient's plight if his scientific judgments are to be morally defensible and suited to the life of a particular patient.

Truthfulness - because the patient is owed the knowledge necessary for making informed choices, so he can make plans for his own life when disease disrupts those plans, and so he can assess his doctor's competence to undertake what he proposes (Pellegrino, 2002, p381).

Rhodes and Pellegrino's accounts of the virtues of medicine are both focused on the attributes of the doctor. Virtues such as truthfulness, courage, and nonjudgmental regard are not just about tendencies. They are character traits, dispositions, or attributes that function as the mindset that informs choices, decisions, and actions. 
However, the concept of virtue as a character trait needs to be augmented with the Aristotelian concept of phronesis (moral or practical wisdom). A virtue or a character trait on its own may lead to excessive and or overbearing behavior, which could lead to ethically and morally harmful consequences! For example, extreme courage may lead to irresponsible desperado actions, which may have bad effects. Truthfulness, compassion, intellectual honesty, nonjudgmental regard may all be good moral virtues. Still, in making use of them, agents ought to exercise practical and ethical wisdom to make the right choices.

And this is where the cultural virtues of the profession play an essential role in lending context to relying on virtues in medicine.

\section{THE VIRTUES OF THE PROFESSION}

Communities and societies formulate and promote shared standards for the regulation of the conduct of their members. This is usually done on various fronts: through legal rules and standards, through rules of morality nurtured in the family, religions, etc. Therefore, developing and sustaining a good community or a good society is predicated upon the need to go beyond individuals to the level of sociological and communal needs as a group (Gbadegesin, 2007). Consider, for example, the virtue of trust, which is regarded as an essential character trait for doctors to have. As Rhodes and Pellegrino rightly observe, trust is at the center of most doctorpatient relationships. It is necessary to various decisions and choices that patients and other actors within the medical profession must make. But trust is not just a virtue for doctors. An excellent medical society will also aim to encourage trust, not merely because it wants patients to increase their trust in doctors but also because it wants to cultivate a better community. Therefore, a good community of doctors will aim to cultivate virtues that are in line with the virtues of medicine itself, which is to promote the health, wholeness, and wellness of patients.

As a community of doctors, institutions such as the General Medical Council (GMC) sets and defines general characteristics of what counts as good medical practice. But in addition to determining the virtues of good medical practice to which it will hold its members, the GMC also engages in various activities to cultivate some of the virtues it upholds. What are the virtues of a good doctor? Who is a good doctor? What sorts of training are available for a good doctor? What sort of teaching and training provisions is available for doctors? These are all concerns that the GMC takes seriously.

It is important to note that, although laws play an essential role in the cultivation and nurturing of these virtues, a substantial part of these virtues are promoted by social activities that are not regulated by law. The main methods by which the virtues of a good profession are nurtured are various association methods and techniques such as social reinforcement and other societal institutions.

Therefore, a virtues-based approach to medical ethics also has to reflect upon the institutional and cultural values of the community of doctors. So, whether trust is a part of the virtues of doctors to a large extent depends on the nature of medicine as a biological discipline itself. Still, it is also, to a large extent, dependent upon the types of associations that doctors engage in. Differently put, social institutions are indispensable to the identification, characterization, nurturing, and evaluation of the virtues and values of medicine. Social institutions such as the GMC are never virtue neutral, and in assessing the virtues of a good doctor, the virtues set and accepted by the GMC will undoubtedly influence the virtues of a good doctor. Although the precise combination of values obtained by social institutions such as the GMC will vary over time, the central point is that these institutions are never valued neutral as they will always be informed by one particular set of values or the other. 


\section{ABORTION IN ISLAMIC ETHICS}

According to one scholar, "The question for Muslims is not whether is right or wrong, from an ethical standpoint, to engage in abortion. Rather, Muslims ask the shar'ah (Islamic law) to sanction abortion and proceed accordingly." (Ebrahim, 2021). In contrast to the Islamic approach, abortion has for long captivated our attention in Western cultures because it raises several moral issues. It raises questions about the value of life; it raises questions about women's rights, the rights (if any) of the fetus and the rights (if any) of the father. At the heart of these questions are the issues of when human life begins and whether abortion amounts to the killing of potential life. In some extreme cases, a doctor may be faced with the unenviable situation of choosing which life to save. All of these are moral and ethical questions - at least, from the Western perspective. How then can abortion be said not to raise ethical questions for Muslims?

To understand the Islamic position on abortion, we need to set it within the conceptual framework from which decisions of life and death would be considered in Islamic culture (Brockopp, J.E. 2003). The fundamentals of Islam can be divided into the pillars of faith (i.e., the beliefs in the Divine Unity of Allah; the centrality of prophecy, revelations, angelic agency, and judgment in the afterlife); and the pillars of practice (i.e., Shahada or witnessing of the belief that there is no god but Allah; praying five times a day, fasting, alms-giving, Hajj, and Jihad). The pillars of faith and the pillars of practice are mutually reinforcing because the elements of faith are not just conceptual contents of the belief that remain in the minds of Muslims. Instead, they are meant to be inculcated into the believers' practice (Elias 1999). Hence, they are intended to be the compass based on which Muslims guide their day-to-day activities. This makes Islam a practice-based religion in which the pillars of faith function as heuristics action-guiding (or decision making) principles for use in daily praxis.

Put together, the pillars of faith and practice have important consequences on abortion. First, the belief in God's divine unity or oneness (tawhid) means that humans participate in God's oneness. As such, humans are active participants in God's relationship with the world (Elias 1989). Since believers consider the Qur'an to be God's words, the Qur'an serves as God's purposive commands. But since the Qur'an does not contain explicit instructions (or injunctions) on all types of situations concerning which practical action-guiding directions might be sought, a hierarchy of decision-making tools has been developed for ethical issues. These go as follows: the Qur'an; Hadiths (which contain examples of how the Prophet Muhammad dealt with similar situations); whether there is consensus on the issue by Islamic Jurists (the Ulema); and then arguments by analogy which require extrapolations and inductive reasoning from the previous three sources above. So, if the Qur'an is silent on an issue, guidance would be sort from the Prophet's examples. If no guidance can be found from the Prophet's examples, they see if the Ulema can reach a consensus agreement. But if no such agreement can be had, inductive analogical reasoning would be employed (Bowen 2003, Katz 2003).

Even though the Qur'an is silent on the issue of abortion, it makes it clear that for Muslims, the fetus is "ensouled" on the $120^{\text {th }}$ day from conception (Ebrahim 1989). With many Islamic schools of thought, this has led to the conclusion that abortion is allowable in all situations before ensoulment. But after ensoulment, the decision has to be made on a case-by-case basis, and this will require an admixture of reasoning that is based on: other explicit injunctions from the Qur'an, the Prophet's example, the consensus of the Ulema, and arguments from analogy. The clear-cut implication of this is clear (at least, for many Muslims): in situations where abortion is being contemplated, consult an expert in Islamic reasoning to decide how the mixture of these four elements on the hierarchy of the decision-making matrix would resolve the dilemma (Bowen 2003, Katz 2003, Ebrahim 1989). 
Differently put, for most Muslims, there is no need to ponder the moral issues of abortion as such. All that is required is to consult an expert in Islamic reasoning to find out whether, in this case, abortion is justified! To say that "for Muslims, abortion is not a moral issue" is therefore not to claim that the decision eschews moral reasoning. Instead, it's to say that the ethical reasoning has been pushed one step back from the actor (i.e., the person who is considering the abortion) to the reasoner (i.e., the Islamic jurist, or text, or another source) that is being consulted for practical guidance. Reasoning in abortion cases, therefore, function more or less in the same way we consult the law to find out what to do in situations where we are not sure of what the law is! Instead, I accepted the judgment of the trusted Ulema, who will consider these ethical issues and their implications.

My objective in this paper is not that of evaluating the nature of Islamic medico-ethical reasoning. No doubt, a lot could be discussed on this issue. For example, the nature of authority; the validity (by this, I mean the moral worth or standing) of God's commands as contained in the Qur'an; the nature of inductive and analogical reasoning in Islam, etc. These are all fascinating issues in their own right. Nonetheless, my interests here are in exhibiting the point that incommensurable systems of ethical decision making (such as those of Islamic religious thinking and Western secular philosophical traditions) share, at a level, a more fundamental similarity. I have already shown that the virtues of fidelity to trust, benevolence; intellectual honesty; courage; compassion; and truthfulness apply to medico-ethical decision-making in Western philosophical traditions. The preceding indicates that they do apply to Islamic ethical decisions as well. The Islamic expert who goes through the hierarchy of decision-making matrix invites the carrier's trust who is contemplating abortion, and the carrier cannot avoid having this trust as it is essential if an Islamic decision is to be made. The same applies to all the other virtues. Given the cultural goods of medicine, my view is that all the different cultural factors that filter into decision-making in specific cases can be evaluated based on virtues such as these.

\section{THE PROBLEM OF RELATIVISM}

Different cultures assume different conceptions of virtues, and hence the virtues which inform medico-ethical decision-making in one society will differ from those that inform those of another community. Indeed, concerning the same society, the values that are adopted will change over time. Hence, while abortion in all contexts may have been regarded as immoral in the United Kingdom 300 years ago, it is no longer regarded as wrong in all contexts by the generality of people today. If virtues are allowed to play an essential role in medical ethics, won't we end up with relativism and irrationalism?

As I have already argued above, medicine is a cultural good in any culture. That is, medicine is about the use of exemplary techniques that have been learned, nurtured, and transmitted in a society in such a way that these unique techniques become part of the community and individual methods for the moderation, regulation, and control of action and inaction in issues of health, wholeness, and wellness. So even though there might be significant variations in the particular virtues and values accepted in any specific medical culture, the focus on the medical wellbeing of patients is a value that all cultures will share. This suggests that although there may be a lot of disagreement about the specific virtues that ought to inform medical ethics, this disagreement is due to misunderstandings or different interpretations of the virtues themselves. So, the virtues themselves are not relative; our understanding, application, and interpretation of them are.

But even if the values are not themselves relative, we still need to explain and account for how rationality can be maintained in medico-ethical decision making if various conflicting virtues can 
play essential roles in ethical decision making. Differently put, the problem is this: supposing society $A$ (or culture $A$ ) accepts a set of assumptions $\left\{T_{1} \& M_{1} \& V_{1}\right\}$ (where $T_{1}$ is a set of theories about causes and effects of illnesses and diseases; $M_{1}$ is a set of methods for carrying out medical procedures and tests, and $V_{1}$ is a set of virtues). Even if a different society accepts the same set of theories, methods, and virtues, it may arrive at a different conclusion on choice and ethical appraisal. This is because, to adopt a phrase from H.L.A. Hart, the standards of medico-ethics decision making are "open-textured." To say that standards are open-textured means that a specific rule, principle, or virtue has some vagueness about it. Almost every word or concept in every language has numerous meanings or definitions. In one context, a decision-maker might apply and use a meaning that is different from that adopted by another decision-maker. This is precisely why ethical decision-making does not operate like deductive logic. The methods and theories of medicine are more or less the same in most Western Countries, but people arrive at different conclusions on the morality of aborting, euthanasia, etc. Since medicine is a cultural good in all societies, the set of virtues of each culture will include amongst its specific virtues the six cultural goods we have identified above. Even when virtues differ radically, these cultural goods will function as universal virtues against which ethical decision-making can be made.

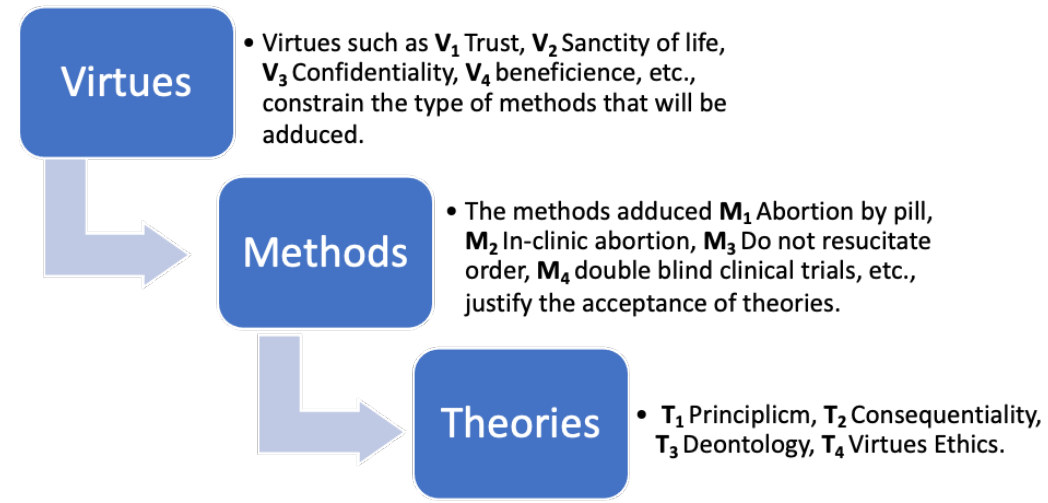

What we will then end up with is a reticulational (see Laudan 1984) account of rationality in which there can be widespread disagreement and differences amongst various elements of scientific (but in this case also cultural) commitments, but in which, because there are sufficiently similar virtues that are in line with the overall aims and goals of science, it would still be possible to have trans-cultural evaluations amongst different cultures. In all cultures and paradigms of medicine, because the cultural goods of medicine form part of the virtues of every culture, these virtues will partially regulate and control methodological choices, just as much as they will regulate and control theoretical and specific decision-making. Therefore, rationality in medico-ethical decision-making would depend on a reticulational process of mutual justification amongst the various levels of cultural commitment. Rational decision-making becomes a reasoning process in which virtues, aims, methods, principles, rules, and factual assumptions play an essential role in the decision-making process.

The significance of this is that no longer should we regard principles and rules as privileged, or primary, or more fundamental than the virtues of our profession. Virtues, principles, methods, factual and rules become intricately connected in relations to mutual dependency in medicoethical decision making. 
To be more precise, although my emphasis on the roles of virtues and cultures in medical ethics commits me to an account in which there may be significant differences in the specific virtues that are adopted by particular cultures, these differences are not as revolutionary as they might sound because although one culture may be composed of a paradigm $\left\{T_{1} \& M_{1} \& V_{1}\right\}$ and another culture may be made of paradigm $\left\{T_{2} \& M_{2} \& V_{2}\right\}$, this view is not one of the incommensurable commitments because $V_{1}$ and $V_{2}$ would share the specific virtues $V_{a}, V_{b}, V_{c}, V_{d}, V_{e}$, and $V_{f}$ (where $V_{a}$ $\ldots V_{f}$ are the cultural goods of medicine).

\section{CONCLUSION}

This paper is a critique of principlism, the view that ethical principles can be resolved by reference to ethical principles and nothing else. My argument has been that two crucial cultural contexts legitimize principles: the profession of medicine itself (which requires doctors to be trustworthy, nonjudgmental, keep secrets, etc.), and the specific cultures of the societies within which the decision-maker is operating. In contrast to the dominant approach to medical ethics (an approach in which principles, rules, and the consequences of agents' actions are the only essential factors in medical ethics), I have maintained that virtues (or moral character) are required for all medicoethical decision-making. But the virtues of importance are not just the virtues of individuals as agents. The virtues of medicine itself and the values of general society are also crucial in how we reason our way through medico-ethical dilemmas. I have illustrated these points with examples from Western and Islamic scholarship. In particular, using the example of abortion in Islam, I demonstrated how societies that adopt radically different virtues could arrive at similar decisions on when abortion is justified and when it is not.

I have not claimed that because medico-ethical decision-making ultimately relies on cultural standards, they cannot be assessed, critiqued, rejected, or evaluated. Different types of cultural assumptions of necessity operate in medico-ethical decision-making. But how should these underlying assumptions themselves be evaluated? I have not addressed this axiological question in this paper. The aim of this essay was that of refuting (with concrete examples) principlism. Ethical principles alone are not enough for resolving medico-ethical dilemmas. Ethical principles are not enough. Virtues and cultures are also required for effective medico-ethical decisionmaking.

\section{REFERENCES}

Abimbola, K. (2013). Culture and the principles of biomedical ethics. Journal of Commercial Biotechnology, 19(3), 31-39.

Abimbola, K. (2007). Medicine and culture: transcultural needs in modern Western societies. Clinical Risk, 13(3), 112-117. https://doi.org/10.1258\%2F135626207780559897

Abimbola, K. (2002). Questions and answers: the logic of preliminary fact investigation. Journal of Law and Society, 29(4), 533-559. https://doi.org/10.1111/1467-6478.00232

Anscombe, G. E. M. (1958). Modern moral philosophy. Philosophy, 33(124), 1-19.

Barnes, J. (2004). The Nicomachean ethics. Penguin.

Beauchamp, T. L. \& Childress, J. F. (2001). Principles of biomedical ethics. Oxford University Press.

Bowen, D.L. (2003). Contemporary Muslim ethics and abortion. In J. E. Brockopp (ed). Islamic ethics of life: Abortion, war, and euthanasia. University of South Carolina Press.

Brockopp, J. E. (2003). Islamic ethics of life: abortion, war, and euthanasia. University of South Carolina Press.

Chervenak, F. A., McCullough, L.B. \& Kurjak, A. (Eds.). (1999). Professional virtues in the Clinical care of the fetus as a patient. In F. Chervenak, and A. Kurjak (Eds). Fetal medicine: The clinical care of the fetus as a patient. C.R.C. Press. 
Eagleton, T. (2000). The idea of culture. Blackwell Publishing.

Ebrahim A.F.M. (1995) Abortion. In The Oxford Encyclopedia of the Modern Islamic World. Oxford University Press.

Ebrahim, A. F.M. (1989). Abortion, birth control, and surrogate parenting: An Islamic perspective. American Trust Publications.

Elias JJ. (1999) Islam. Prentice-Hall.

Gardiner, P. (2003). A virtue ethics approach to moral dilemmas in medicine. Journal of medical ethics, 29(5), 297-302. http://dx.doi.org/10.1136/jme.29.5.297

Gbadegesin, S. (2007). The moral weight of culture in ethics. In L. Prograis Jr and E.D. Pellegrino (eds.) African American Bioethics: Culture, race, and identity. (pp. 25-46). Georgetown University Press

Gripsrud, J. (1989). 'High culture' revisited. Cultural studies, 3(2), 194-207. https://doi. org/10.1080/09502388900490131

Harding, S. (Ed.). (1975). Can theories be refuted? Essays on the Duhem-Quine thesis (Vol. 81). Springer Science \& Business Media.

Katz, M.E. (2003). The problem of abortion in classical Sunni figh. In Brockopp, J. E. (ed). Islamic ethics of life: Abortion, war, and euthanasia. University of South Carolina Press.

Laudan L. (1984). Science and values: The aims of science and their role in scientific debate. University of California Press.

Locke, A. (1989). The ethics of culture. In L. Harris (ed.) The philosophy of Alain Leroy Locke: Harlem Renaissance and beyond, (pp. 175-186). Temple University Press.

Macintyre A, (1981). After Virtue. Duckworth.

Pellegrino, E. D. (2002). Professionalism, Profession and the Virtues of the Good Physician. The Mount Sinai Journal of Medicine, 69(6), 378-384.

Pellegrino, E. D., \& Thomasma, D. C. (1993). The Virtues in Medical Practice. Oxford University Press.

Rhodes, R. (2007). The Professional Responsibilities of Medicine. In The Blackwell Guide to Medical Ethics. (pp71-87). Blackwell Publishing,

Rhodes, R. (2001). Understanding the Trusted Doctor and Constructing a Theory of Bioethics. Theoretical Medicine and Bioethics, 22(6), 493-504. https://doi.org/10.1023/a:1014430208720

Rhodes, R. (1995). Love Thy Patient: Justice, Caring, and the Doctor-Patient Relationship. Cambridge Quarterly of Healthcare Ethics, 4(4), 434-447. https://doi.org/10.1017/So963180100006253

\section{AUTHOR}

Kola Abímbola. Associate Professor of Philosophy. Ph.D. in Philosophy of Science (London School of Economics and Political Science, United Kingdom). Ph.D. in Law of Evidence and Criminal Justice (University of Birmingham, United Kingdom). LLB Laws (London School of Economics and Political Science, United Kingdom). B.A. First Class Honors in Philosophy (Obafemi Awolowo University, Nigeria)

\section{Conflict of interest}

No potential conflict of interest is reported by the author.

Funding

No financial assistance from parties outside this article.

\section{Acknowledgments}

$\mathrm{N} / \mathrm{A}$ 